\title{
COVID-19 pandemic planning: considerations for radiation oncology medical physics
}

\author{
May Whitaker $^{1} \cdot$ Tomas Kron $^{2,3,4} \cdot$ Matthew Sobolewski ${ }^{5,6} \cdot$ Richard Dove $^{7}$
}

Received: 2 April 2020 / Accepted: 6 April 2020 / Published online: 13 April 2020

(c) Australasian College of Physical Scientists and Engineers in Medicine 2020

\section{Background}

On 8 December 2019 a case of pneumonia with unknown etiology was discovered in Wuhan City, Hubei Province in China [1]. By 30 January 2020 the outbreak was declared a Public Health Emergency of International Concern [2]. The new coronavirus disease was named COVID-19 on 11 February 2020 [3] and a month later it was characterised by the World Health Organisation (WHO) as a pandemic due to the rapid spread and severity of the disease and perhaps more alarmingly, a lack of action [4].

The rapid global impact of COVID-19 is unprecedented and unexpected. In Australia and New Zealand, we have not experienced a contagion of this nature on our shores in modern times and it highlights a great deal of planning and forethought that has not previously been undertaken. With governments now urgently trying to flatten the epidemic curve [5] and hospitals preparing for the impending onslaught of critically ill, infected patients, we must consider the effects and impact of containment and mitigation measures applied by our governments.

In Radiation Oncology, our cancer patient cohort includes some of the most vulnerable to serious illness if infected with COVID-19: the elderly, the immunosuppressed, those

May Whitaker

May.Whitaker@lh.org.au

1 Chris O'Brien Lifehouse, Sydney, Australia

2 Department of Physical Sciences, Peter MacCallum Cancer Centre, Melbourne, Australia

3 Sir Peter MacCallum Department of Oncology, University of Melbourne, Melbourne, Australia

4 University of Wollongong, Wollongong, Australia

5 Riverina Cancer Care Centre, Wagga Wagga, Australia

6 Northern Beaches Cancer Care, Sydney, Australia

7 Canterbury District Health Board, Christchurch, New Zealand with compromised lung function [6], and often those with all three. Yet radiotherapy remains an essential service amidst the pandemic.

In most departments, Radiation Oncology Medical Physicists (ROMP) have direct patient contact in various clinical areas such as brachytherapy, in vivo dosimetry, motion management etc., hence it is essential that we stand prepared to support the department to the best of our abilities whilst minimising infection risk to our staff and our patients. Without direct prior experience of dealing with a pandemic, we are grateful for the documentation of the difficult and tragic experiences of our ROMP colleagues in Singapore following the Severe Acute Respirator Syndrome (SARS) outbreak in 2003 [7], and the general emergency responses of the 2010 Haiti [8] and 2011 Christchurch and 2016 Kaikoura earthquakes [9], and the Puerto Rico hurricane of 2017 [10]. In contrast to many of these experiences the COVID19 pandemic provides a brief preparation window before the maximum effects are felt, allowing us valuable time to organise and implement a cohesive plan for staffing and activity reductions.

ROMP work and workforce planning must be integrated into the wider radiation oncology care planning. It is likely that the radiation oncology patient load will be reduced due to hospital policies minimising outpatient visits and different risk/benefit judgements in a pandemic environment. Fractionation may also be changed. Physics staffing must be aligned to these changes which may necessitate, or at least facilitate, changes to rosters and work practices such as working from home (WFH), protecting vulnerable staff and essential quality assurance (QA).

This paper aims to provide practical considerations for ROMPs in an Australian and New Zealand context, when planning the ROMP work and workforce in the face of a pandemic. These considerations are not complete and may not all be applicable to every department, but it is hoped that their application, as appropriate to each department's unique modus operandi, will instil confidence in the workforce that 
their safety and wellbeing is a priority, and allow continuity of uncompromised care to our patients.

\section{Considerations for ROMP work and workforce planning}

\section{Organising work}

Medical Physics is a unique workforce characterised by a large variety of relatively complex tasks. Compared to radiation therapists (RT), nurses and radiation oncologists (RO), physicists' direct patient contact is limited. On the other hand, medical physics is typically the smallest of the professional groups with the least redundancy built in and often the smallest office space. In the context of disaster planning it is therefore helpful to separate the tasks into several categories:

1. Patient facing (eg brachytherapy, special procedures, motion management, in vivo dosimetry)

2. Safety assessments (eg radiation safety monitoring, QA after repairs)

3. Patient specific calculations and measurements without direct patient contact

4. (Routine) radiotherapy treatment equipment calibration, QA and testing (includes testing of physics equipment such as radiation monitors and ion chambers)

5. Treatment plan reviews and planning advice

6. Projects and project management (includes commissioning of new equipment)
7. Teaching, education, research

8. Administration (includes payroll, rostering, leave management, counseling)

The relative contribution to the different areas varies significantly from clinic to clinic but the categorisation allows the development of distinct response models. Table 1 provides some considerations and aims to categorise the activities into separate groups based on priority for, and availability of, medical physics resources. The grouping is also informed by the way the services can be managed:

- Group A requires experienced staff on site during treatment hours-patient facing

- Group B requires staff on site outside of normal working hours-non-patient facing

- Group C requires experienced staff-can be done remotely

- Group D can be done remotely by a mix of staff

Group A are essential services. Not all clinics will deliver services that require physicists to be present at simulation, imaging or treatment. However, if this is the case it is prudent to identify two teams that work segregated from each other so if one team is out of action, the second can take over. It is generally not practical to supplement these teams with staff from other campuses or institutions because the techniques and procedures will be very specific to the clinic, and to maintain separation to minimise risk of cross

Table 1 Considerations for organising different tasks typically undertaken by medical physicists working in radiation oncology

\begin{tabular}{|c|c|c|c|c|}
\hline Tasks & Group & Relevance during crisis & Consideration & Comment \\
\hline Patient facing & A & $\begin{array}{l}\text { Essential—cannot be delegated } \\
\text { or cancelled }\end{array}$ & Need to be on site, PPE & $\begin{array}{l}\text { Similar role to other clinical } \\
\text { professions }\end{array}$ \\
\hline Safety assessments & A & $\begin{array}{l}\text { Essential—cannot be delegated } \\
\text { or cancelled }\end{array}$ & & $\begin{array}{l}\text { In general a small part of the } \\
\text { workload }\end{array}$ \\
\hline $\begin{array}{l}\text { Patient specific measurements } \\
\text { without direct patient contact }\end{array}$ & B & $\begin{array}{l}\text { Important—could be prioritised } \\
\text { according to patient needs }\end{array}$ & $\begin{array}{l}\text { To be done out of hours or } \\
\text { offsite }\end{array}$ & $\begin{array}{l}\text { Working from home or at times } \\
\text { without any patients or other } \\
\text { staff present }\end{array}$ \\
\hline Machine calibration and testing & B & $\begin{array}{l}\text { Important-could be prioritised } \\
\text { according to impact on safety }\end{array}$ & $\begin{array}{l}\text { To be done completely out of } \\
\text { hours }\end{array}$ & \\
\hline $\begin{array}{l}\text { Treatment plan reviews and } \\
\text { advice }\end{array}$ & $\mathrm{C}$ & Important & Can be done remotely & $\begin{array}{l}\text { Working from home-requires } \\
\text { clear contact points }\end{array}$ \\
\hline Administration & $\mathrm{C}$ & $\begin{array}{l}\text { Essential—more communica- } \\
\text { tion and organisation may be } \\
\text { required }\end{array}$ & Can largely be done remotely & Consider working from home \\
\hline $\begin{array}{l}\text { Projects and project manage- } \\
\text { ment }\end{array}$ & $\mathrm{D}$ & Reduce frequency and/or cancel & $\begin{array}{l}\text { Commissioning of major equip- } \\
\text { ment can continue if staffing is } \\
\text { adequate }\end{array}$ & $\begin{array}{l}\text { Documentation may be com- } \\
\text { pleted at home }\end{array}$ \\
\hline Teaching, education, research & $\mathrm{D}$ & Reduce frequency and/or cancel & $\begin{array}{l}\text { Trainees/Registrars to be consid- } \\
\text { ered according to experience } \\
\text { and need }\end{array}$ & $\begin{array}{l}\text { Research staff and students can } \\
\text { work from home }\end{array}$ \\
\hline
\end{tabular}


infection. In order to trace activities, a log should be kept of each staff/patient interaction detailing task, location and duration. This allows tracing of contacts if required.

The second task area, safety, is more general and qualified staff from another institution could support or take over the tasks if the local team fails. In any case, activities of group A can only be performed by qualified physicists.

Group B tasks are the most common tasks that ROMPs perform and are acknowledged for: machine and patient specific quality assurance. Both these activities must be overseen by qualified staff but can be performed out of normal hours to minimise interaction with other hospital staff. Appropriate cleaning of rooms and equipment is required prior and post performance of the tasks which can also be performed by junior staff and trainees (under appropriate supervision). Tasks in group B also lend themselves to a degree of prioritisation where the most important activities are performed first. A useful consideration when prioritising is that quality assurance generally has two main objectives: (a) avoidance of major incidents and errors, and (b) quality improvements. Priority must be given to activities that ensure safety.

If appropriate IT systems are in place (remote access to hospital network and treatment planning system), Group C activities can be performed largely remotely and workers can be rostered to work offsite. Telephone access is essential to facilitate consults and communication with planning staff and colleagues. Clear lines of communication must be established that allow others to access medical physics services, wherever they may be physically located.

Offsite may refer to a group setting remote from the clinic (eg another part of the hospital), or individuals working from home. A group setting enhances teamwork and may provide easier access to IT infrastructure, while working from home minimises travel. It is essential to ensure continuing good work practices and ideally a Work Health and Safety (WHS) assessment of the home workplace should be performed. It is also good practice to have all workers, independent of their work location, attend a virtual meeting for rollcall in the morning to discuss the daily work and ensure home workers are coping and have adequate resources to perform their assigned tasks. A similar virtual meeting can be considered for the late afternoon. Also consider virtual meetings during lunch or outside of work hours with an informal, social aspect to maintain the team's sense of bonding and inclusion.

Administration activities, in the case of a pandemic, become crucial as information must be concise and comprehensive, protective measures need to be put in place and staff fears and concerns need to be addressed. Also, timely and effective communication with other staff groups is of paramount importance. As such, administrative workloads are likely to increase. Good planning for emergencies and transparent processes (accompanied by regular revision and possibly training) can help but it is difficult to predict the exact nature of the emergency and some degree of improvisation may be required.

Tasks of Group D can cover a large range of activities. As many of them are not necessarily mission critical, they can be reduced to the most important ones. However, these activities, in particular training and commissioning, can actually make the work more effective and as such help in the response to the emergency. Trainees can be of great value in maintaining some services (type B in particular) provided they are adequately trained and prepared. It is only appropriate that good documentation of their involvement is credited towards their training record.

Clinical research and physics research activities that require access to treatment equipment are significantly affected and likely to be reduced or cancelled. However, many research activities such as computer modelling and documentation/writing up are not affected and lend themselves to offsite work. Some institutions may also consider training research staff to perform clinical work in case of significant staff shortages. This needs to be considered on a case by case basis.

\section{Practical considerations}

Table 2 provides a list of practical details for work, workforce and equipment resource planning. It is by no means an exhaustive list, but rather aims to provide a summary of considerations.

\section{Discussion}

The experience of Mukherjee et al. [7] during the 2003 SARS outbreak in Singapore describes potential outbreak interventions in Radiation Oncology. They recommend service protection by rationalising patient contact, restricting staff intra- and inter-hospital movements, creating staff teams and minimising contact between the teams, and periodically reviewing all interventions implemented [7]. These form the basis of a robust protection pathway and consideration must be given to the planning and implementation of these recommendations.

As ROMPS, our work is governed and mandated by national and international guidelines, legal obligations and best practice. The ROMP team pandemic planning is underpinned by these and appropriate decisions should be made based on each state, territory or country's requirements. Further, given the uniqueness of each ROMP team such as the number and experience of staff, allocation and scheduling of work, inclusion of other staff disciplines such as radiation 
Table 2 Practical considerations for work, workforce and equipment resource planning

\begin{tabular}{|c|c|c|}
\hline Category & Subcategory & Considerations \\
\hline \multirow[t]{4}{*}{ Equipment } & Treatment and physics equipment & Clean or sterilise before and after physics use \\
\hline & $\begin{array}{l}\text { Equipment in patient contact e.g. Motion } \\
\text { management, brachytherapy, in vivo } \\
\text { dosimetry }\end{array}$ & $\begin{array}{l}\text { Re-evaluate which equipment is essential for treatment/QA to proceed } \\
\text { Clean or sterilise before and after physics use and between patients }\end{array}$ \\
\hline & Radiation safety equipment & $\begin{array}{l}\text { Ensure radiation monitors and all interlocks are fully functional } \\
\text { Be aware of infection control risk at personal monitor changeover }\end{array}$ \\
\hline & Cleaning agents & $\begin{array}{l}\text { Determine which ones are suitable for each type of equipment } \\
\text { Include cleaning of IT equipment and mobile phones }\end{array}$ \\
\hline \multirow[t]{7}{*}{ IT } & Laptops \& monitors & $\begin{array}{l}\text { Availability, necessity (do staff have personal devices that can be used if } \\
\text { WFH or offsite) }\end{array}$ \\
\hline & Phones & $\begin{array}{l}\text { Staff WFH will be expected to receive and make calls } \\
\text { Is there a work mobile phone available or call forwarding facility }\end{array}$ \\
\hline & Accessory hardware & $\begin{array}{l}\text { Access to or provision of microphone, speakers/earphones and video } \\
\text { camera are essential for videoconferencing. These capabilities are often } \\
\text { deactivated on hospital computers for security purposes and may need } \\
\text { to be activated }\end{array}$ \\
\hline & Connectivity & $\begin{array}{l}\text { Remote access available, internet access from home of good quality and } \\
\text { sufficient bandwidth, test prior to WFH }\end{array}$ \\
\hline & Workplace & $\begin{array}{l}\text { Be aware of WHS and infection control at work and in the home environ- } \\
\text { ment }\end{array}$ \\
\hline & Cybersecurity & $\begin{array}{l}\text { Consider Virtual Private Network (VPN) keys or other unauthorised } \\
\text { access inhibitors, how to share patient information such as images, } \\
\text { datasets or QA results online } \\
\text { Home computers need to have appropriate protection, following institu- } \\
\text { tion's IT security policies }\end{array}$ \\
\hline & Privacy in tele and videoconferencing & $\begin{array}{l}\text { Zoom and Skype are not secure portals, patient identifiers should not be } \\
\text { mentioned }\end{array}$ \\
\hline \multirow[t]{7}{*}{ Staff and visitors } & Resourcing & $\begin{array}{l}\text { Evaluate necessary on- and offsite staffing to align with changing patient } \\
\text { workload. Consider different options to support the department whilst } \\
\text { maintaining team safety, eg keep the same staff on one team and rotate } \\
\text { at set periods with an entirely different team, or designate a patient } \\
\text { contact team and a non-contact team, with a thorough cleaning program } \\
\text { at team changeover }\end{array}$ \\
\hline & Knowledge and skills & $\begin{array}{l}\text { Identify any skills and knowledge gaps within the workforce and address } \\
\text { as a matter of priority, in order to allow clinical services to continue. } \\
\text { Protocols and procedures may need to be written or revised rapidly }\end{array}$ \\
\hline & Social isolation and mental health & $\begin{array}{l}\text { Recognise the isolation of staff WFH, consider regular video or telecon- } \\
\text { ference meetings }\end{array}$ \\
\hline & Contact tracing & $\begin{array}{l}\text { In case of an unknown infected patient, rigorously record all activities } \\
\text { involving patient contact so that contact tracing may be expedited }\end{array}$ \\
\hline & Maintaining collaboration and culture & $\begin{array}{l}\text { Develop activities, meetings or other interactive methods such as team } \\
\text { chat groups on social media (eg Whatsapp) to maintain a sense of team } \\
\text { and teamwork. Encourage a healthy culture in isolation }\end{array}$ \\
\hline & Absences & $\begin{array}{l}\text { Plan to maintain services with a gradual reduction in numbers due to sick } \\
\text { leave or carer's leave for the school/childcare cohort } \\
\text { Be aware of the institution's staff absence policies, particularly in regards } \\
\text { to taking leave for self isolation, child minding or caring for a sick rela- } \\
\text { tive etc }\end{array}$ \\
\hline & Health & $\begin{array}{l}\text { Ensure any staff feeling ill are not physically present, comply with } \\
\text { hospital safety precautions such as daily temperature screening; anyone } \\
\text { with COVID-19 symptoms to be tested. Evaluate staff for any particular } \\
\text { health vulnerabilities and roster appropriately if necessary } \\
\text { Mental health must be considered; develop strategies to minimise isola- } \\
\text { tion, stress and anxiety }\end{array}$ \\
\hline
\end{tabular}


Table 2 (continued)

\begin{tabular}{ll}
\hline Category & Considerations \\
\hline External audits & $\begin{array}{c}\text { Delay if possible, or in urgent cases have the second team or physicists } \\
\text { unaffiliated with the original commissioning or QA work perform an } \\
\text { independent check } \\
\text { Remote audits (eg by thermoluminescent (TLD) or optically stimulated } \\
\text { (OSL) dosimeters) should be considered } \\
\text { Audit groups and colleagues from other hospitals will likely be prohibited } \\
\text { from visiting your site } \\
\text { Consider periodic (eg 2 week) on/off or contact/non-contact team rota- } \\
\text { tions to align with ROs and RTs, consistent with incubation periods } \\
\text { and hospital policies, to coordinate departmental response. Adequately } \\
\text { assess cross contaminations from rotations eg if patient/staff A is in con- } \\
\text { tact with both teams (before and after rotation) and tests positive, both } \\
\text { teams may require isolation. A stringent hand-over protocol is required } \\
\text { Particular care should be given to common areas and facilities such as tea } \\
\text { rooms and water taps }\end{array}$
\end{tabular}

Visitors

Training and research Medical Physics Registrars/Trainees

Research

Continuing Professional Development (CPD)

QA

Scheduling

Jurisdiction

Reduced workforce

Safety Functionality of equipment
Minimise visitors by prohibiting students and non-essential people

Ensure essential contractors are aware of any screening requirements and comply with all hospital directives in regards to health and safety

Consider performing some tasks with remote support from company service personnel

Reduced patient loads may leave treatment equipment free for training and testing activities. Consider registrar training needs when creating rosters and plans to account for trainers in the same team, or activities that may be patient or non patient related

Reduced ROMP clinical work may allow for research, project or analysis type activities to continue from home or in a non patient contact environment

Continuing Professional Development is essential to the ROMP role and may easily be performed either on or offsite

Decide what is fundamental to safety, legally required and essential for treatment, prioritise the remainder according to resource constraints. Consider adopting more efficient workflows or methods that require less time on site eg analyse data remotely

Prioritisation criteria must be communicated to other staff

If not already done so, move QA and nonessential work to weekends and out of hours, or cancel

Consider a conservative time frame for the overall impact of pandemic induced restrictions or reductions: eg if the situation continues for 3 months, monthly QA cannot be deferred

Provide schedules to other staff indicating these arrangements, noting flexibility or non negotiable decisions

Be aware that ultimate responsibility for equipment being fit for purpose and safe for treatment lies with medical physics

Consider RTs, Radiation Engineers/Biomedical Engineers performing some QA to minimise physics contact on machine, as appropriate to each department. This must be reviewed by physics and should be clearly identified as a temporary measure

Consider which craft groups are able to perform various QA activities and allocate tasks to minimise cross contamination risk and exposure of critical staff

Ensure tasks that are handed over are well documented including action and tolerance levels

Consider how much QA can be done by the existing workforce

Plan for reduced workforce scenarios, eg $80 \%, 50 \%$ and $20 \%$

Preventative or routine maintenance and QA schedule to ensure equipment works for its intended purpose 
Table 2 (continued)

\begin{tabular}{|c|c|c|}
\hline Category & Subcategory & Considerations \\
\hline & Useability of equipment & $\begin{array}{l}\text { Preferentially use equipment that can be sterilised quickly and safely, or } \\
\text { single use only }\end{array}$ \\
\hline & Radiation safety & $\begin{array}{l}\text { With changes to workflow and staff rosters, consider if this impacts on the } \\
\text { safety of patients, staff and visitors }\end{array}$ \\
\hline & Resourcing constraints & $\begin{array}{l}\text { When staff numbers decrease, consider which functions and activities } \\
\text { may be safely suspended without compromising patient care. Be pre- } \\
\text { pared to cancel services }\end{array}$ \\
\hline \multirow[t]{3}{*}{ Patient related } & Close contact & $\begin{array}{l}\text { Activities requiring physics presence such as brachytherapy, total body } \\
\text { irradiation and total body electron treatments: reduction or suspension } \\
\text { of these activities are clinical decisions-ROMPs can assist with a risk } \\
\text { assessment. Some tasks can be shared with RT staff } \\
\text { Consider in vivo dosimetry activities with passive detectors (TLD) as } \\
\text { opposed to active detectors such as semiconductors that may require } \\
\text { physics presence } \\
\text { Can other staff such as RT perform all or some of the duties required } \\
\text { Selected physics staff will need to be familiar with personal protective } \\
\text { equipment and other safety measures-identify staff that require training }\end{array}$ \\
\hline & Sterilisation & How to sterilise equipment such as dosimeters pre and post patient usage \\
\hline & Equipment & $\begin{array}{l}\text { Consider grouping all patient types on a single machine, plan for reduced } \\
\text { operations }\end{array}$ \\
\hline \multirow[t]{4}{*}{ Communication } & Documentation & $\begin{array}{l}\text { Report on activities that have been suspended to allow the contingency } \\
\text { plan to be executed }\end{array}$ \\
\hline & Updates & $\begin{array}{l}\text { Ensure transparency and clear communication to all staff members includ- } \\
\text { ing those WFH } \\
\text { Ensure clear and precise informative handover at the roster rotation, eg } \\
\text { updates on breakdowns, particular patient specific issues etc } \\
\text { Communicate physics changes and requirements in the broader depart- } \\
\text { mental context }\end{array}$ \\
\hline & Timeframes & $\begin{array}{l}\text { Keep track of when activities have ceased and when they will resume } \\
\text { again }\end{array}$ \\
\hline & Review & $\begin{array}{l}\text { Consider all of the above in developing a Pandemic Plan, then set a time- } \\
\text { frame to review and adjust decisions accordingly. Accept that flexibility } \\
\text { and adaptability are called for in a crisis and that decisions and plans } \\
\text { may change frequently }\end{array}$ \\
\hline \multirow[t]{5}{*}{ Management } & Procurement & $\begin{array}{l}\text { Prioritise purchasing as appropriate to the departmental needs, eg (1) } \\
\text { Patient care, (2) Safety, (3) Enabling effective WFH equipment }\end{array}$ \\
\hline & Service Continuity & $\begin{array}{l}\text { Ensure a clear understanding of service provider's ability to maintain } \\
\text { contracted services and the effect any travel restrictions may have on } \\
\text { their spare parts and labour resources }\end{array}$ \\
\hline & Budgeting & $\begin{array}{l}\text { Difficult to plan for a financial year that may or may not be in the midst } \\
\text { of a pandemic. Prioritise capital expenditure requirements according to } \\
\text { departmental and patient needs or legal requirements } \\
\text { Service and maintenance contracts must be accounted for in the budget to } \\
\text { ensure continuation of service. } \\
\text { Keep records of all expenditures }\end{array}$ \\
\hline & Productivity & $\begin{array}{l}\text { Ensure staff who are WFH remain productive and effective, and keep } \\
\text { track of work done, time spent on activities etc }\end{array}$ \\
\hline & Upgrades & $\begin{array}{l}\text { Consider postponing major upgrades if resources are stretched, eg } \\
\text { upgrades to the radiation oncology management system (ROIS) or } \\
\text { Treatment Planning System (TPS) }\end{array}$ \\
\hline
\end{tabular}

or biomedical engineers or IT etc., it is difficult to create a single solution plan.

Working from home is an unusual concept for most medical physicists. As a small workforce, ROMPS are used to being needed on site during or after hours. Careful consideration must be given to ensure WFH is an effective and efficient activity. Remote access to essential computer tools such as PACS, ROIS and TPS are essential prerequisites. In addition to this a computerised departmental QA system is beneficial as it allows tracking and monitoring of 
activities performed by the onsite team or other staff groups. Close collaboration with the IT department is important.

The closer ROMPs work with a clinical team, the more useful they can be on the phone. Priority must be given to continuing tasks such as treatment plan checking; however, other activities that lend themselves to remote working are:

- Completion of inservices and CPD activities

- Documentation of work and procedures including future activities (eg commissioning plans for the linear accelerator (linac) next year)

- Evaluating the effectiveness of activities (eg are there any head and neck IMRT plans more likely to fail)

- Detailed planning of future projects including a thorough literature search

- Evaluating potential equipment/software purchases and developing a business case

- Writing software and scripting including developing a governance framwework

- Development of training materials for registrars and others

- Liaison with colleagues in other institutions to standardise procedures

- Writing publications

It must also be understood by the ROMP workforce that other factors may need to be taken into account, such as hospital funding being diverted into priority equipment (eg ventilators), or physicists being requested to assist in other areas of resourcing shortfalls, eg staffing the screening desk at the entry point. Performing essential equipment QA on the weekends may strain the hospital budget in paying weekend penalty rates, and any equipment failures or breakages may not be fixed or replaced unless it is crucial to direct patient care or safety. Supply chain limitations and restrictions on travel may reduce the ability of suppliers and vendors to repair or calibrate equipment. Brachytherapy may particularly be affected as source supply of Ir-192 or low dose rate seeds such as I-125 may be interrupted.

This may not be critical should brachytherapy activities decrease in number of patients or fractionation schedules, or be suspended altogether due to a lack of suitably trained staff, anaesthetics or theatre availability. However, brachytherapy often requires fewer patient attendances than external beam radiotherapy and as such, may be preferable in some circumstances such as gynaecological applications or intraoperative radiotherapy for breast cancer.

Trying to maintain safe workforce numbers amidst school or nursery/daycare closures, increasing personal or sick leave and a mandatory reduction of staff onsite is a delicate balancing act. The plan must also take into account the specific capabilities of each individual, and ensuring the current workforce has the required skills and knowledge to carry out the essential work for safe patient care. A suspension of services may be required in the event that there are insufficient appropriately skilled staff available to safely plan, check and deliver a patient's radiation treatment [11].

Contractors and vendor service engineers who present onsite to perform necessary repairs or preventative maintenance are also responsible for maintaining the plan to reduce transmission and protect our staff and patients. As with all staff and patients, they should undergo the same screening on entry to the department and practise good hand hygiene and social distancing at all times.

The pandemic plan should also address the recovery phase, where the pandemic is declared contained and hospitals, businesses and people around the world commence the long road to recovery. It may be that the department, and indeed the hospital and society as a whole, never return to the pre-pandemic state. Processes and practices that arise during the pandemic may, for better or worse, become the new norm. With an increasing workload managed by a decreasing workforce during the crisis, employers may opt to permanently reduce the workforce citing proven capability to operate at a reduced number. To forestall this, a record of all services and activities suspended during the pandemic should be documented so that management are fully aware of the scope of activities normally required to run the department. It should also be noted that reduced services and activities are correlated with a reduction in patient numbers, and operating with minimal staff numbers for extended periods of time may result in greater burnout and risk of incidents.

Of more immediate concern is the potential for a postpandemic surge in the number of patients requiring treatment [12] - those who were safely deferred at the height of the crisis. A depleted and exhausted workforce may not have the capacity to treat the post-pandemic surge in numbers, therefore the department and team pandemic plan should also factor this in workforce planning.

Debriefing within the team and the department in general is essential so that lessons learned may be noted and acted upon should another pandemic or other state of emergency arise in the future. Equally important are periodic reviews of the processes and plans put in place, to ensure they reflect the current needs and level of service provision.

\section{Conclusion}

A radiotherapy department relies on skilled staff across multiple disciplines, hence pandemic planning must occur in a multidisciplinary environment in order to create a whole department response. Department action levels for a graduated delay or cessation of patient treatment should be based on available staff and resources. For the ROMP workforce 
particular attention must be given to (radiation) safety, equipment, technical and patient contact aspects when creating a pandemic plan, as well as communication to all stakeholders and a longer term view to the management of a post-pandemic surge in the number of patients.

Acknowledgements TK acknowledges helpful discussions with $\mathrm{N}$ Hardcastle and K Gerontzos. MW acknowledges helpful discussions with the Radiation Oncology management team, and the Department of Physics and Engineering at Chris O'Brien Lifehouse.

\section{Compliance with ethical standards}

Conflict of interest The authors declare that they have no conflict of interest.

Ethical approval This article does not contain any studies with human participants or animals performed by any of the authors.

\section{References}

1. Wu Z, McGoogan JM (2020) Characteristics of and important lessons from the Coronavirus Disease 2019 (COVID-19) outbreak in China: summary of a report of 72314 cases from the Chinese Center for Disease Control and Prevention. JAMA. https://doi. org/10.1001/jama.2020.2648

2. WHO (2020) Novel Coronavirus(2019-nCoV) Situation Report - 11. https://www.who.int/docs/default-source/coronaviruse/situa tion-reports/20200131-sitrep-11-ncov.pdf?sfvrsn=de7c0f7_4. Accessed 29 Mar 2020

3. WHO (2020) Novel Coronavirus(2019-nCoV) Situation Report - 22. https://www.who.int/docs/default-source/coronaviruse/situa tion-reports/20200211-sitrep-22-ncov.pdf?sfvrsn=fb6d49b1. Accessed Mar 2020

4. WHO (2020) Novel Coronavirus(2019-nCoV) Situation Report -51. https://www.who.int/docs/default-source/coronaviruse/situa tion-reports/20200311-sitrep-51-covid-19.pdf?sfvrsn=1 ba62 e57_10. Accessed 29 Mar 2020

5. Groch S (2020) How are countries 'flattening the curve' of coronavirus? SMH. https://www.smh.com.au/national/how-are-count ries-flattening-the-curve-of-coronavirus-20200317-p54b3g.html. Accessed 29 Mar 2020

6. Department of Health (2020) What you need to know about coronavirus (COVID-19). Australian Government Coronavirus (COVID-19) health alert. https://www.health.gov.au/news/healt h-alerts/novel-coronavirus-2019-ncov-health-alert/what-youneed-to-know-about-coronavirus-covid-19. Accessed 29 Mar 2020

7. Mukherjee RK, Back MF, Lu JJ, Shakespeare TP, Wynne CJ (2003) Hiding in the Bunker: challenges for a radiation oncology department operating in the severe acute respiratory syndrome outbreak. Aust Radiol 47:143-145

8. WHO (2011) Earthquake in Haiti-one year later: report on the health situation. PAHO/WHO. https://www.who.int/hac/crises/hti/ haiti_paho_jan2011_eng.pdf?ua=1. Accessed 29 Mar 2020

9. Dorahy MJ, Rowlands A, Renouf C, Hanna D, Britt E, Carter JD (2015) Impact of average household income and damage exposure on post-earthquake distress and functioning: a community study following the February 2011 Christchurch earthquake. Br J Psychol 106(3):526-543

10. Gay HA, Santiago R, Gil B et al (2019) Lessons learned from Hurricane Maria in Puerto Rico: practical measures to mitigate the impact of a catastrophic natural disaster on radiation oncology patients. Pract Radiat Oncol 9:305-321

11. Cancer Care Ontario (2020) Pandemic planning clinical guideline for patients with cancer. Ontario Health.https://www.accc-cance r.org/docs/documents/cancer-program-fundamentals/oh-ccopandemic-planning-clinical-guideline_final_2020-03-10.pdf. Accessed 29 Mar 2020

12. Simcock R, Thomas TV, Mercy CE et al (2020) COVID-19: global radiation oncology's targeted response forpandemic preparedness. Clin Transl Radiat Oncol. https://doi.org/10.1016/j. ctro.2020.03.009. Accessed 29 Mar 2020

Publisher's Note Springer Nature remains neutral with regard to jurisdictional claims in published maps and institutional affiliations. 